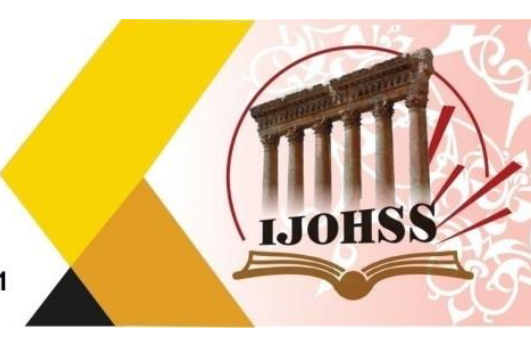

\title{
أدوات الإحالة الداخلية في كتاب مفتاح العلوم وأثرها في ترابط النَّصوص
}

د. فــاطمة محسـمد أميـن خليل

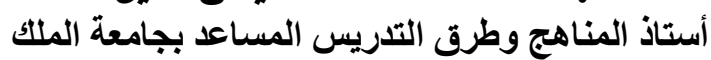
خالد ـ المملكة العربية السعودية ـ ـكلية العلوم والآداب بمحايل عسير

fklel@kku.edu.sa البريد الاككتروني ع

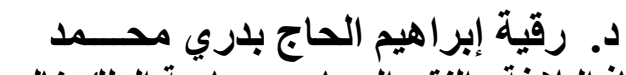

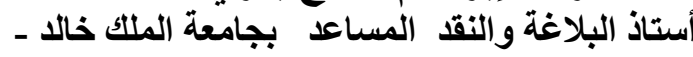

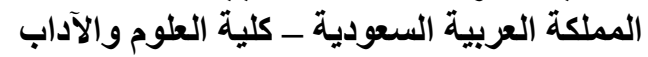
بظهران الجنوب

rhaj@kku.edu.sa البريد الاككتروني:

الملخص

الإحالة من الموضوعات اللغوية المهمة التي تختصُّ بها اللغة العربية، وهي تحبط بكل فروعها؛ وقد حاول هذا

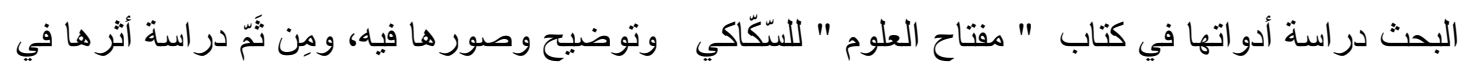
تماسك النّص البلاغي و اتساقه في هذا الكتاب . استطاع المؤلف أن يوظِّف هذه الأدوات في توضيح الفنون البلاغية وبيان فروعها في كل علمِ من علومها

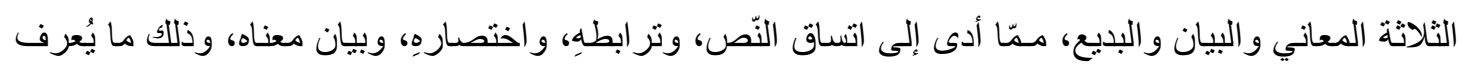
"بالإحالة القبلية " و "الإحالة البعدية. الكلمات المفتاحية: الإحالة، الربط، مفتاح العلوم، السكاكي. 


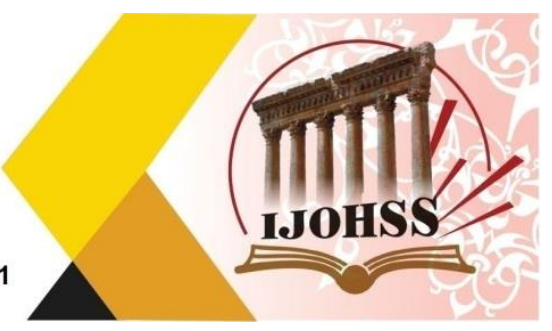

\title{
Internal Referral Tools in the Book of "Miftah Al-Uloom" and their Effect on the Correlation of Texts
}

\author{
Dr. Roqaya Ibrahim Al-Haaj Badri \\ Muhammed \\ Assistant Professor of Rhetoric and \\ Criticism at King Khalid University, \\ Kingdom of Saudi Arabia - College of \\ Science and Arts in Dhahran Al-Janoub \\ Email: rhaj@kku.edu.sa
}

\author{
Dr. Fatima Muhammed Amin Khalil \\ Assistant Professor of Curricula and \\ Teaching Methods at King Khalid \\ University, Kingdom of Saudi Arabia - \\ College of Science and Arts, Mahayel Asir \\ Email: fklel@kku.edu.sa
}

\begin{abstract}
Referral is one of the important linguistic issues that are specific to the Arabic language, and it surrounds all its branches. This research attempted to study its tools in the book "Miftah Al-Ulum" by Al-Sakaki and clarify and illustrate its images in it, and then study its impact on the cohesion and consistency of the rhetorical text in this book. The author was able to employ these tools in clarifying the rhetorical arts and explaining its branches in each of its three sciences: the meanings, the statement and the budaiya, which led to the consistency of the text, its coherence, its abbreviation, and the clarification of its meaning, and this is what is known as "pre- referral" and "post- referral."
\end{abstract}

Keywords: Referral, linkage, key to science, Al-Sakaki. 


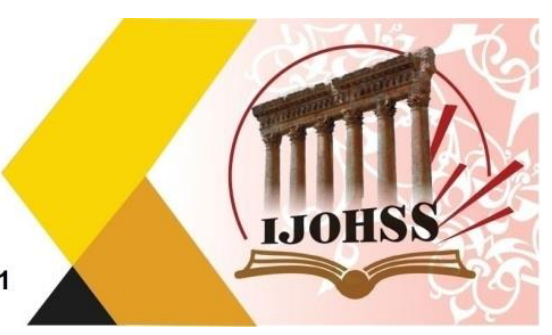

\section{تمهيد:

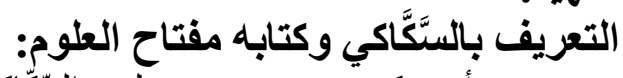

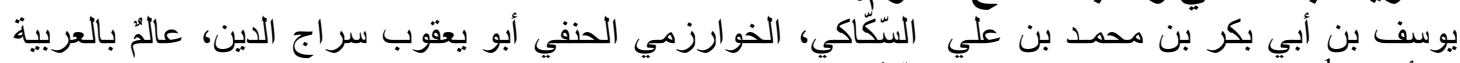

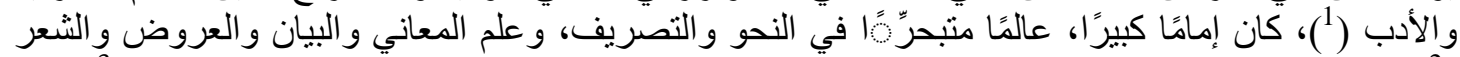

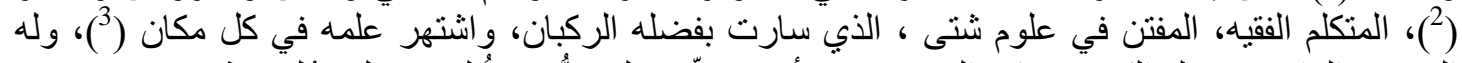

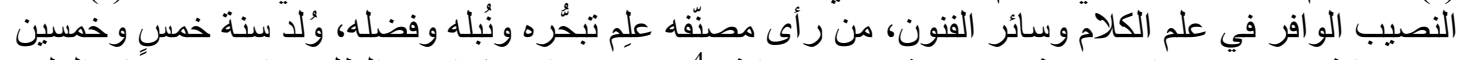

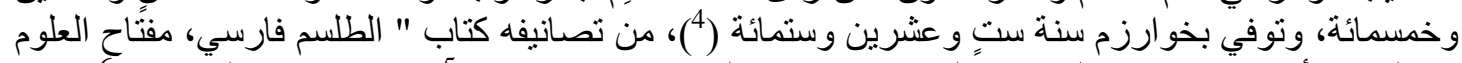

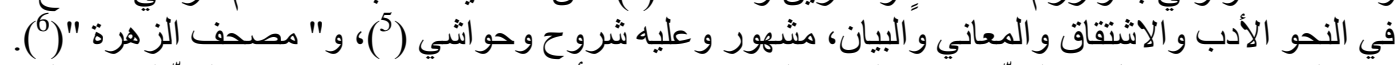

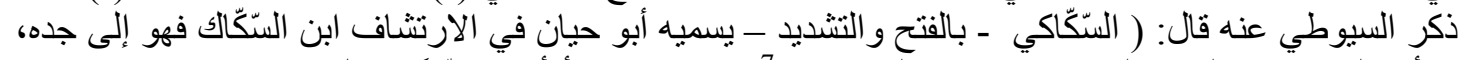

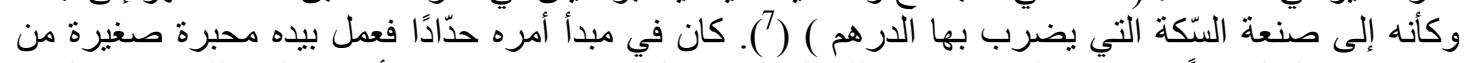

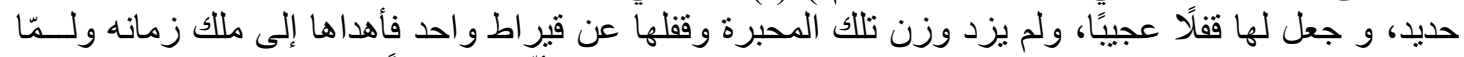

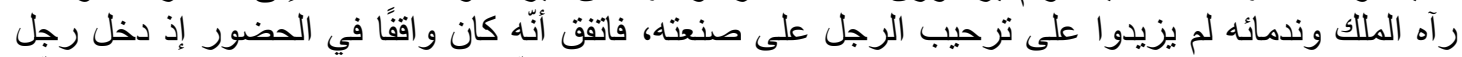

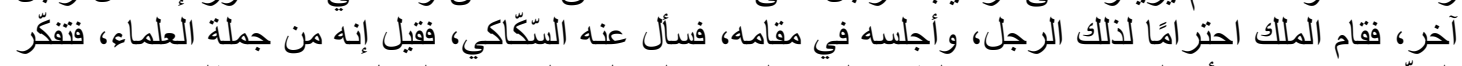

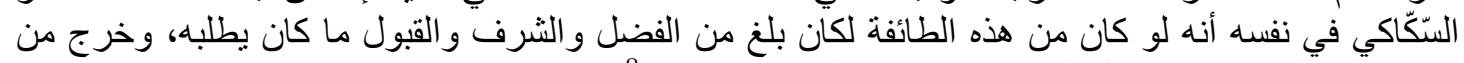

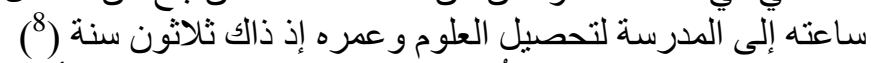

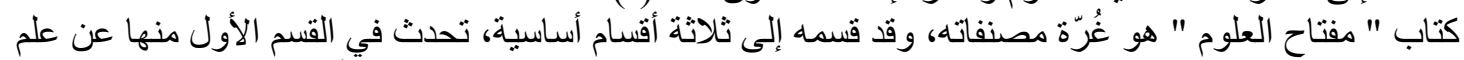

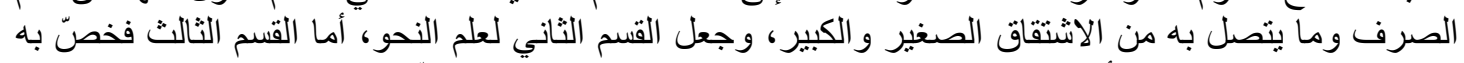

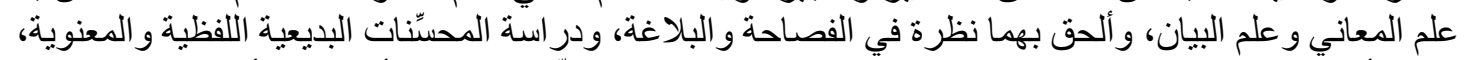

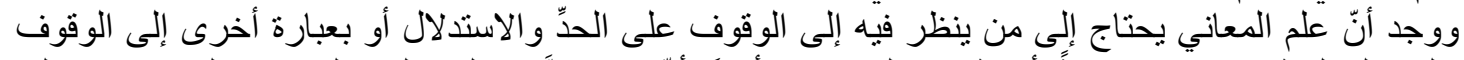

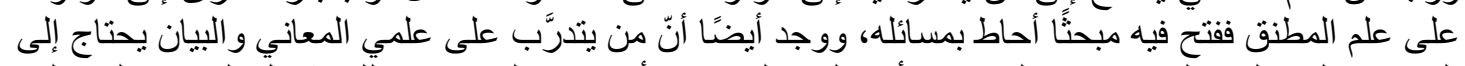

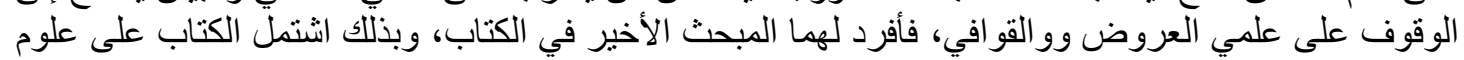

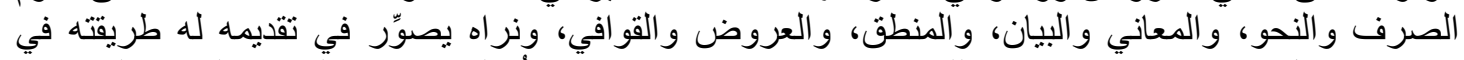

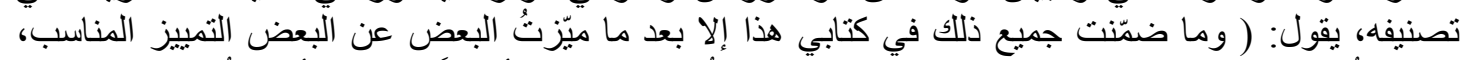

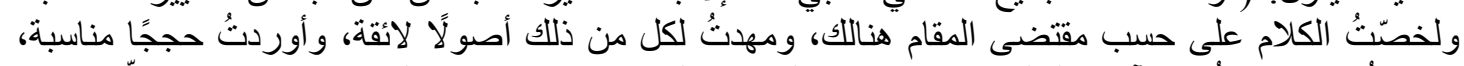

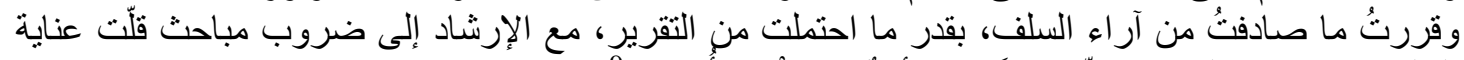

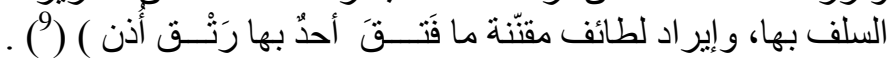

(1) الأعلام قاموس تراجم لأشهر الرجال و النساء من العرب و المستعربين والمستشرقين ، خير الدين الزركلي ( 222/6

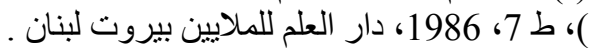

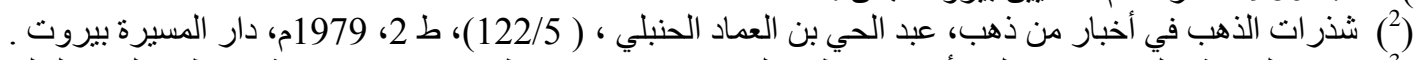

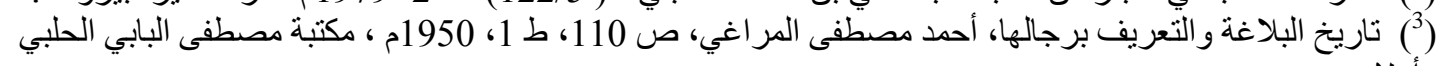
وأو لاده بمصر (4) بُغية الإيضـاح في طبقات اللغويين و النُحاة، عبد الرحمن السيوطي، تحقيق محمــــ أبو الفضل إبر اهيم، ( 364/2) مطبعة عيسى البابي ألحلبي وشركاه (5) هدية العارفين في أسماء المؤلفين و آثار المصنفين، إسماعيل باثنا البغدادي، (553/2) ، وكالة المعارف الجليلة في

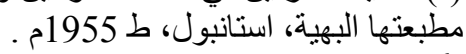

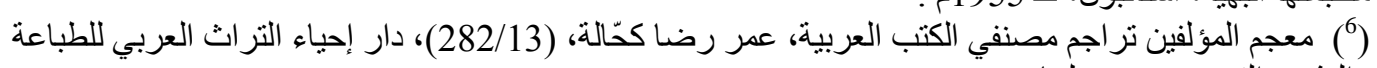

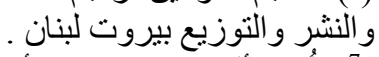

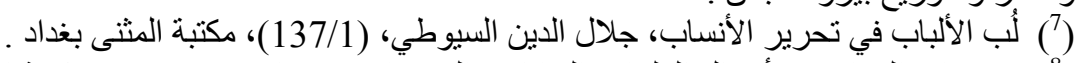

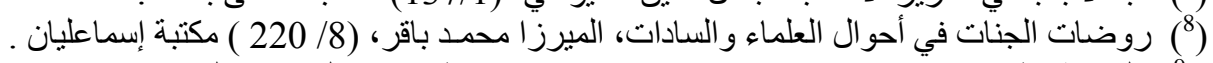
(9) البلاغة تطور وتاريخ، د. شوقي ضيف، صليفاء صات، 287، 288، ط 9، دار المعارف القاهرة . 


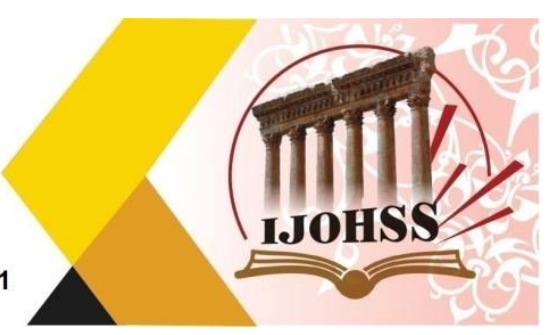

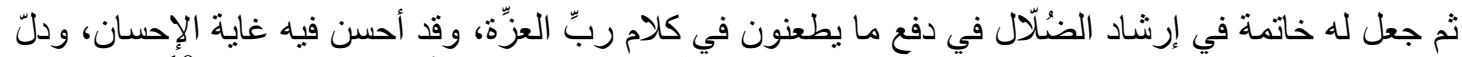

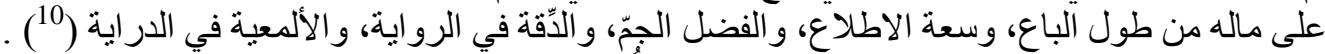

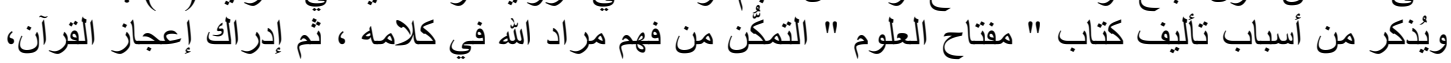

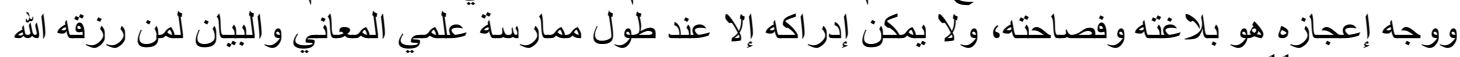

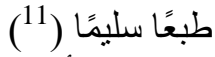

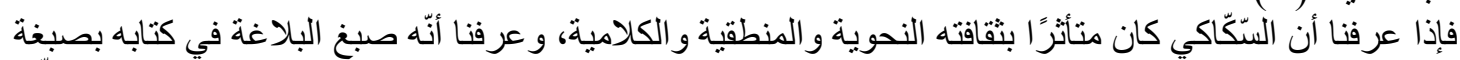

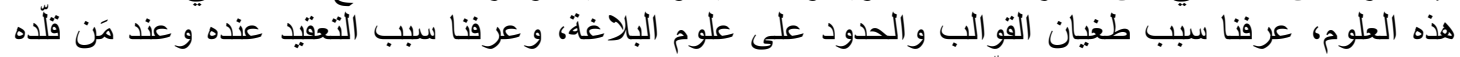

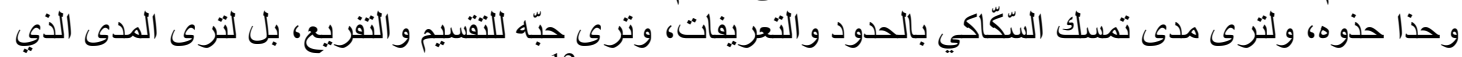

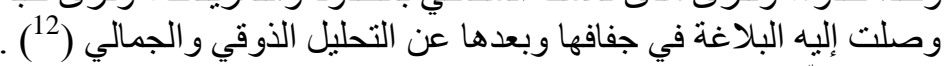

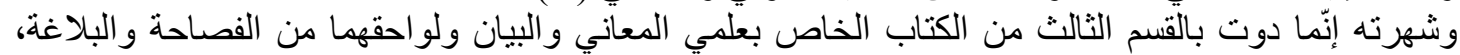

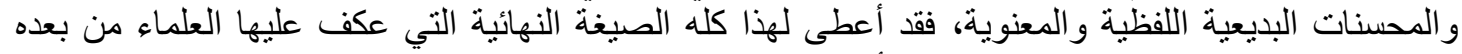

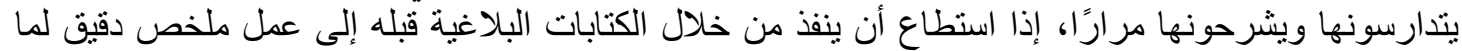

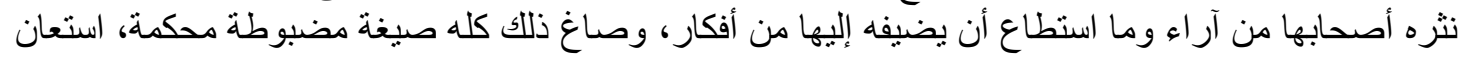

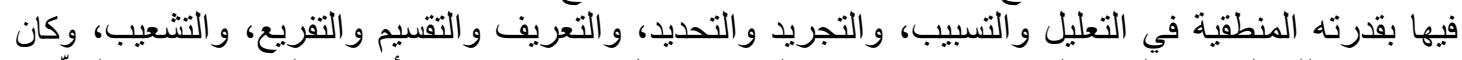

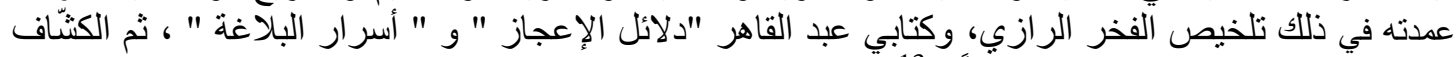

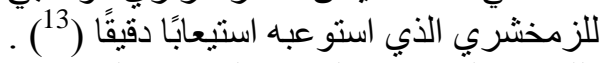

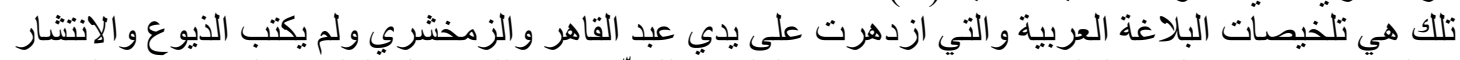

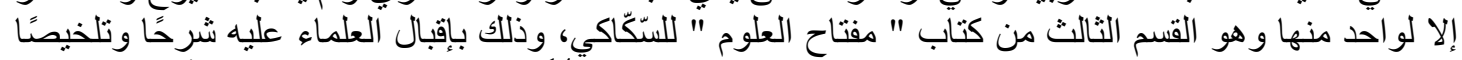

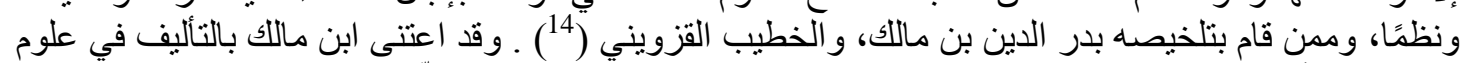

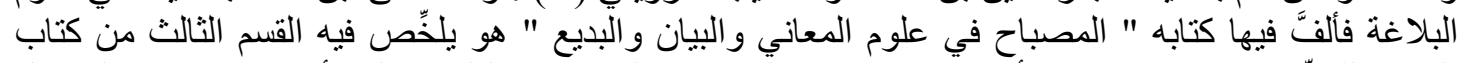

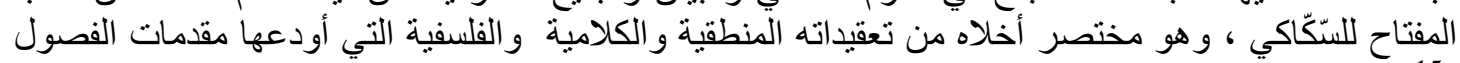

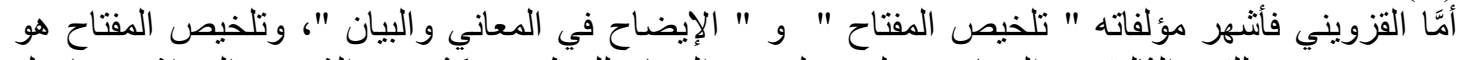

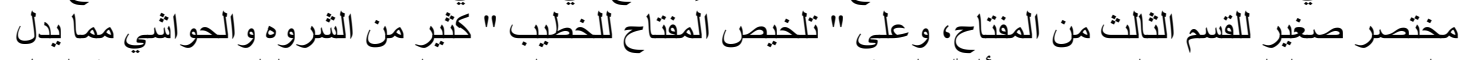

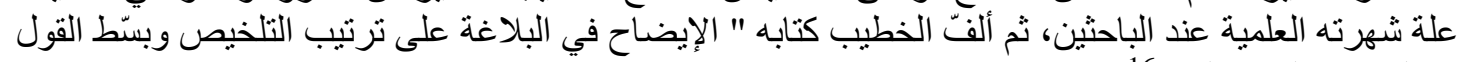

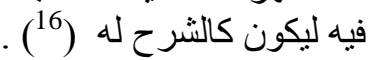

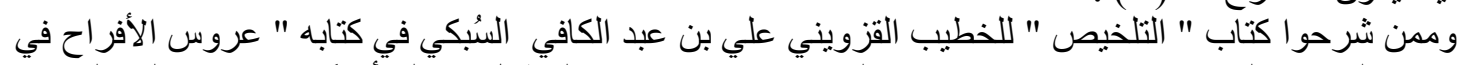

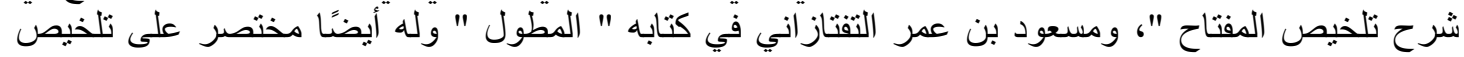

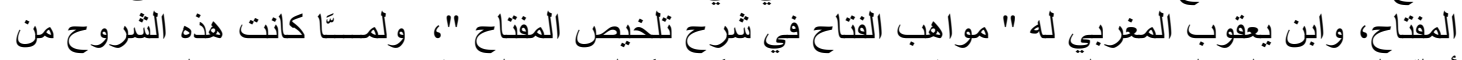

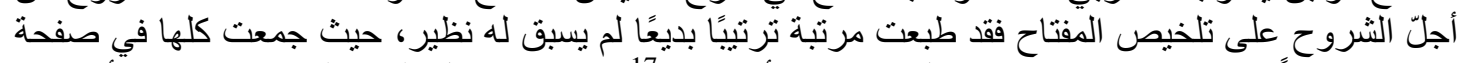

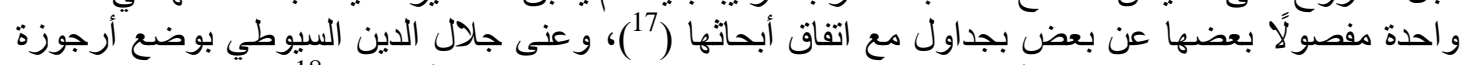

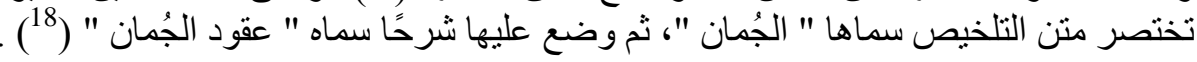

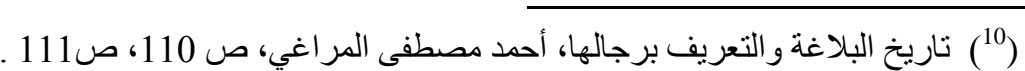

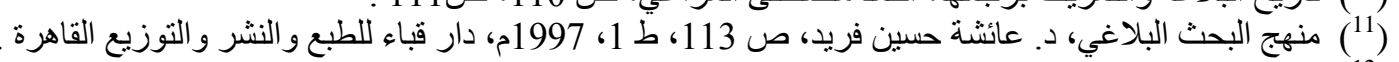

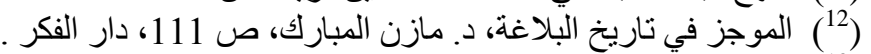

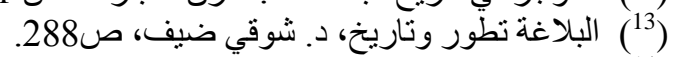

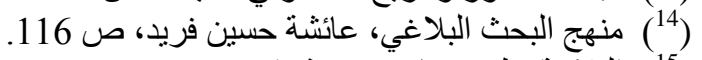

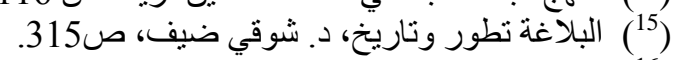

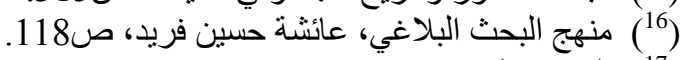

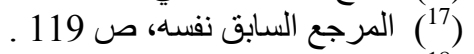

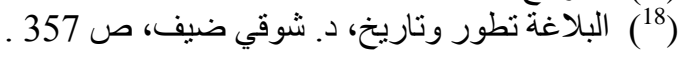




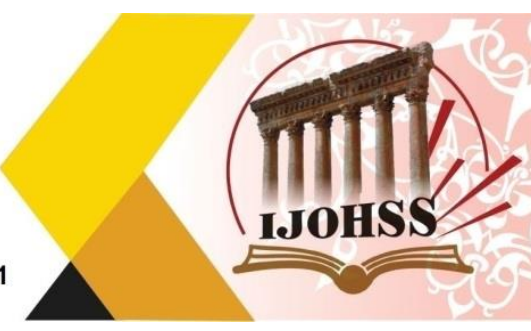

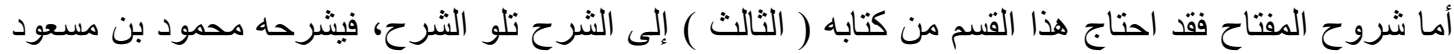

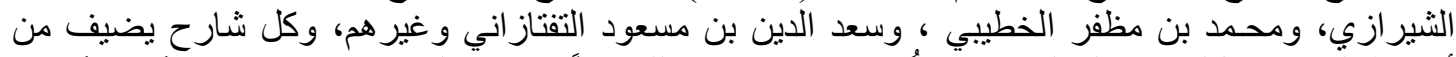

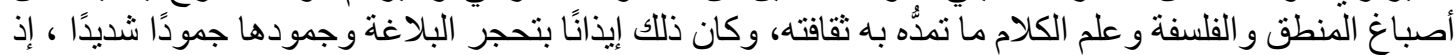

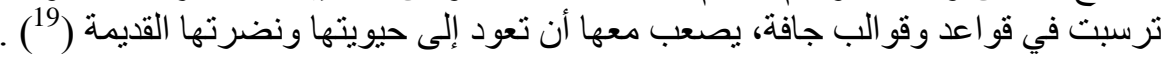

\section{المبحث الأول: مفهوم الإحالة

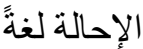

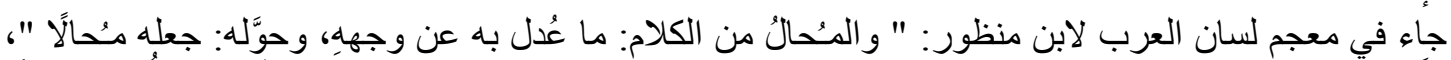

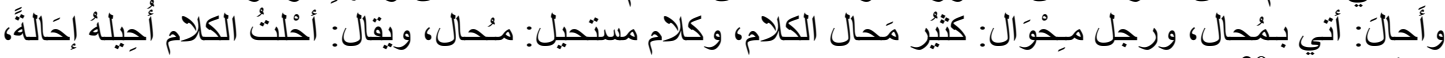

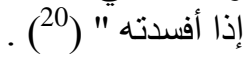

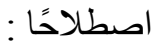

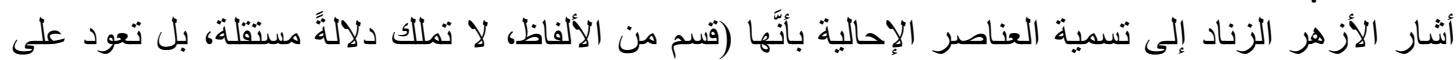

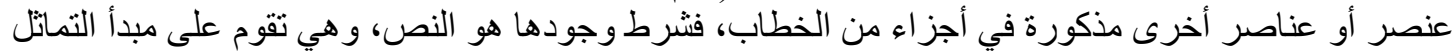

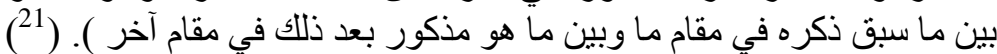

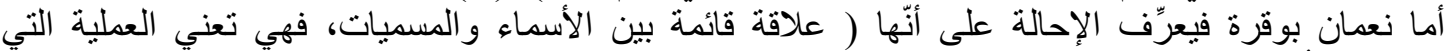

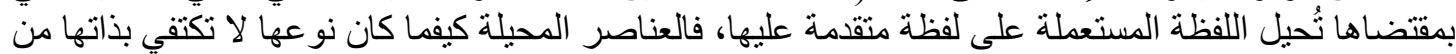

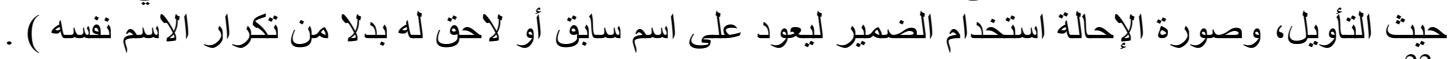

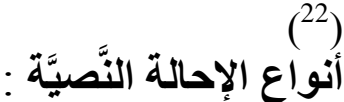
تُعدُّ الإحالة من ألهالة الأهم الوسائل الاتساقية التي تحقّق للنص تماسكه و التحامه، وذلك من خلال الربط بين أجزائه،

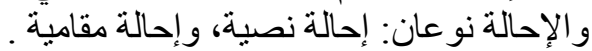
و عليه فيمكن أن تكون عناصر الإحالة مقامية أو نصيَّة، وإذا كانت نصيَّة فإنها يمكن أن إنُّيل إلى إلى السابق أو إلى إلى

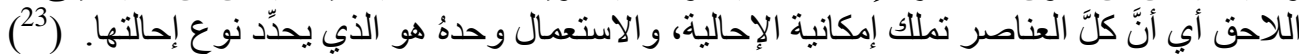

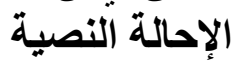
يعرِّفها الأزهر الزيّة الزّاد بأنَّها :( إحالة على العناصر اللغوية الواردة في الملفوظ سابقة أو لاحقة فهي إحالة نصية ) (24).

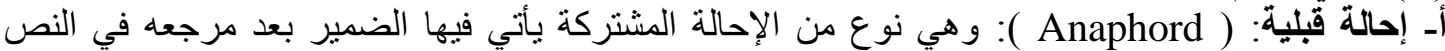

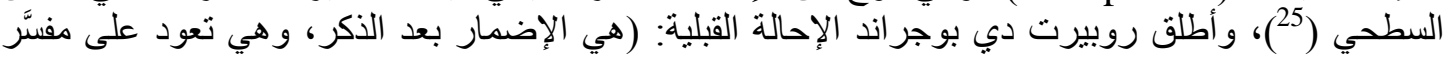

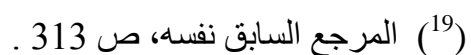

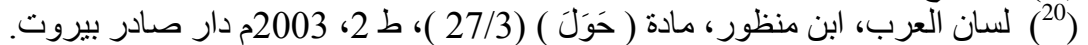

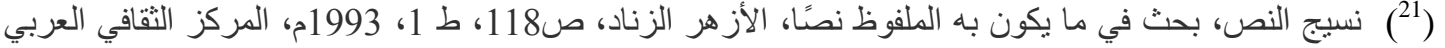

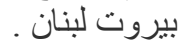
(22) الدصطلحات الأساسية في لسانيات النص وتحليل الخطاب دراسة معجمية، نعمان بوقرة، ص 81، ط1، 2009، عالم

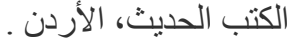
(23) لسانيات النّص مدخل إلى انسجام الخطاب، محدد خطّابي، ص17، ط 3، 2012، المركز الثقافي العربي، الدار

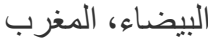
(24) نسيج النص، بحث في ما يكون به الملفوظ نصًا، الأزهر الزناد، ص118 . (25) النّص و الخطاب و الإجر اء، دي بوجر اند، تر : تمام حسان، ص 301، ط 1، 1998، عالم الكتب، القاهرة . 


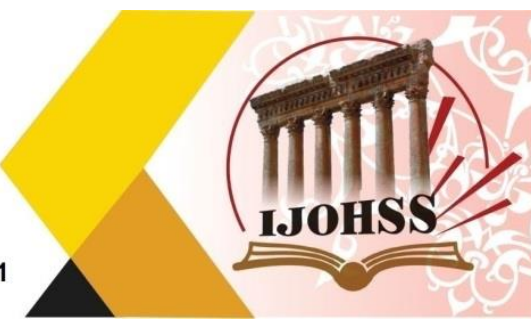

سبق التلفُّط به و هي أكثر الأنواع دورانًا في الكلام (262)، وفيها يثبر العنصر الـُحيل إلى عنصر آخر منقدمًا

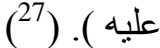

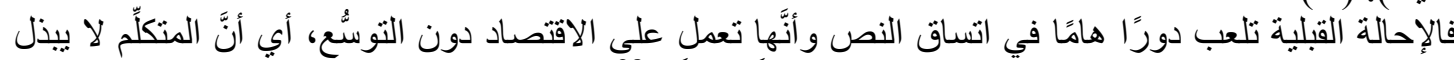

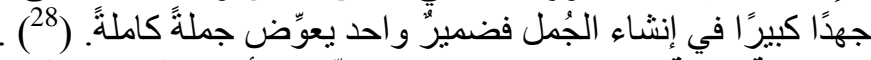

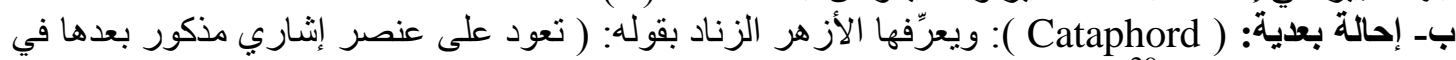

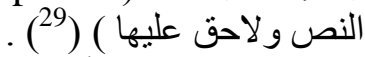

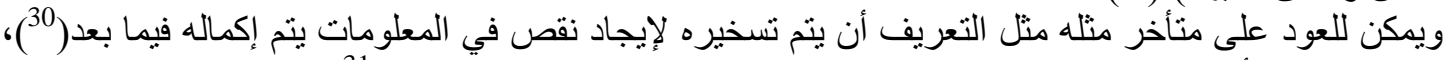

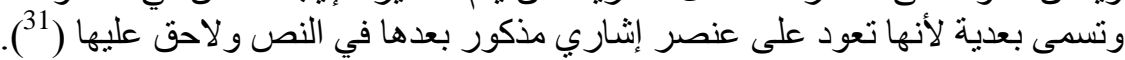

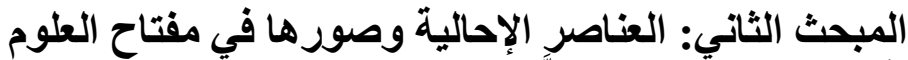

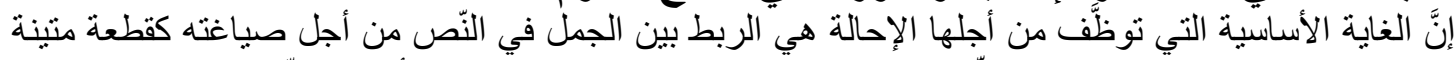

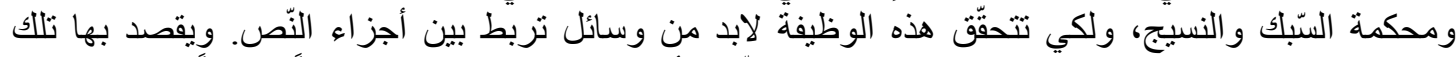

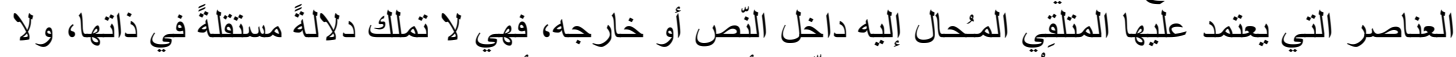

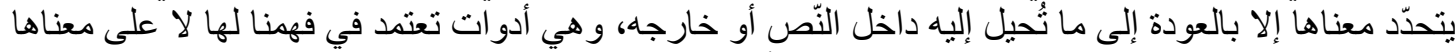

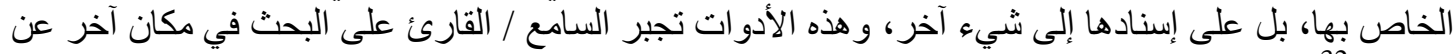

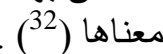

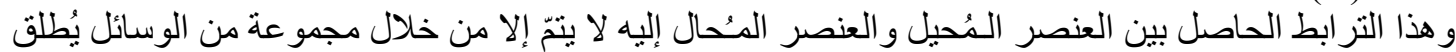

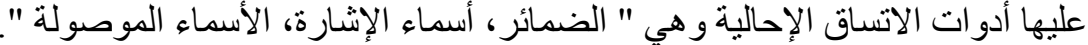

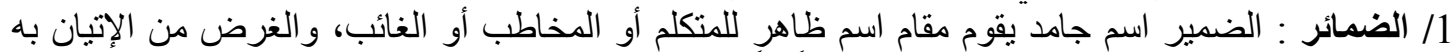

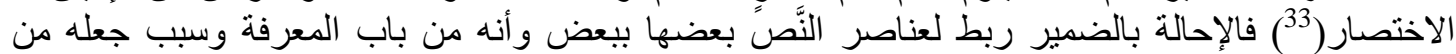

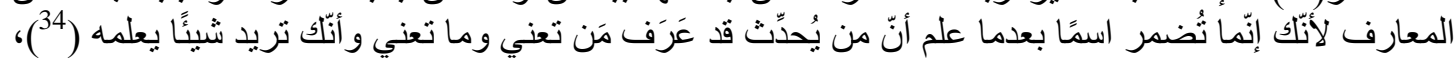

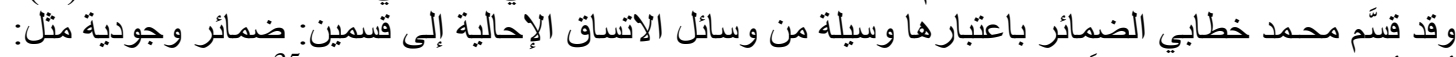

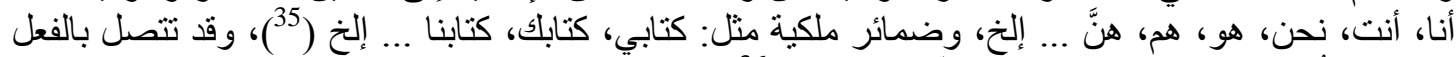

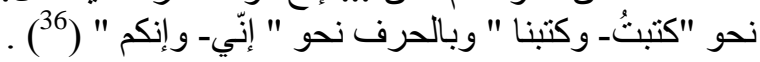

(26) نحو النص اتجاه جديد في الدرس النحوي، أحمد عفيفي ،ص 117، ط 1، 2001، مكتبة زهراء الثروق، القاهرة . (27) علم لغة النص والأسلوب، نادية رمضان النجار، ص 106، ط1، 2013، دار حورس الدولية للنشر والتوزيع،

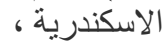

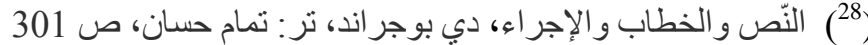

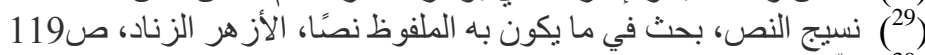

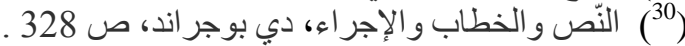

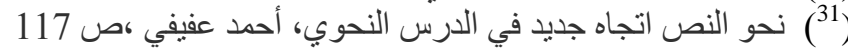
(32) تحليل خطاب، براون ويول، ترل محمد لطفي الزلّيطني ومنير التريكي، ص 230، ط 1997، النشر العلمي و المطابع - جامعة الملك سعود

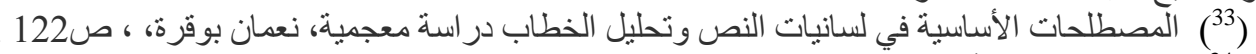

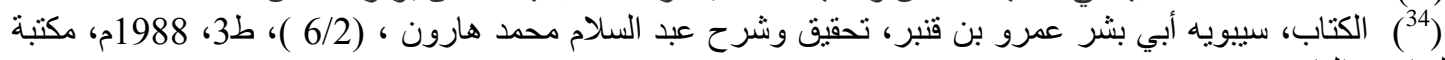

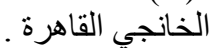

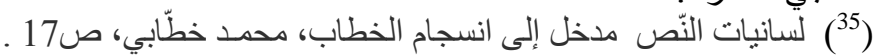

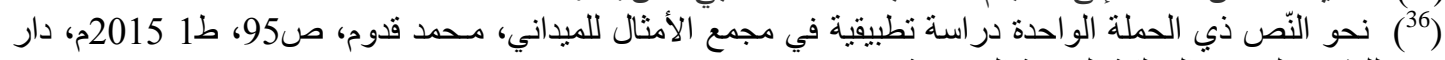

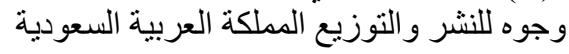




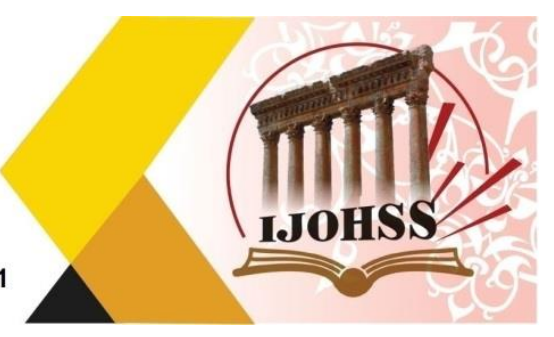

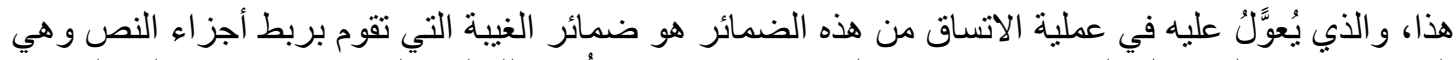

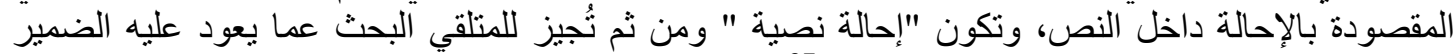

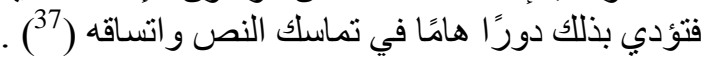

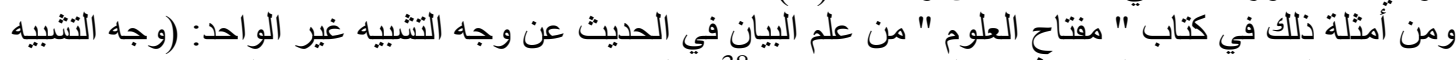

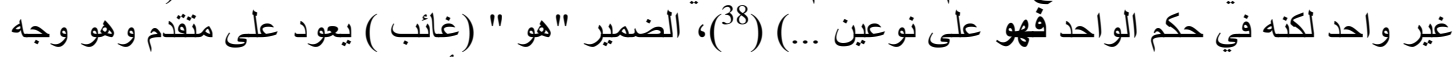

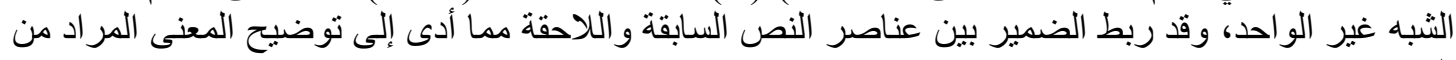

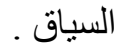

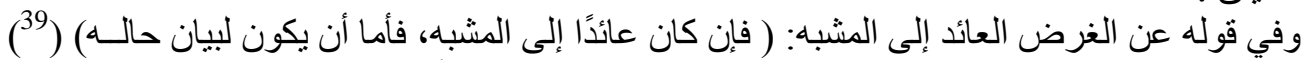

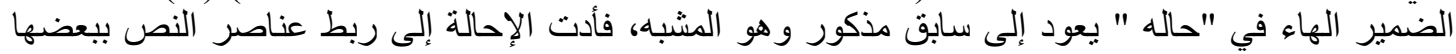

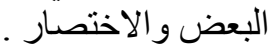
ومن أمثلته في مفتاح العلوم في " علم البديع " في البديع المعنوي: ( ومنه المشاكلة .... ) (404)، الضمير المنصل

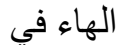
" ومنه " ترجع إلى سابق مذكور وهو القسم المعنوي لعلم البديع، فأدت الإحالة إلى الاختصسار و الربط بين

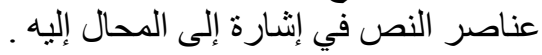

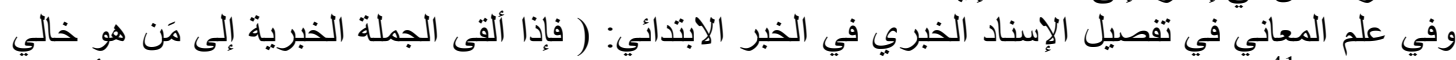

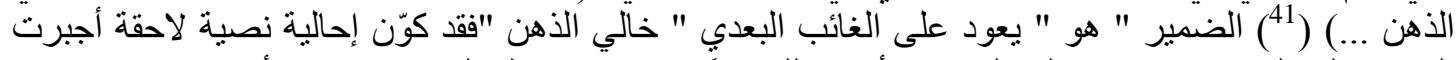

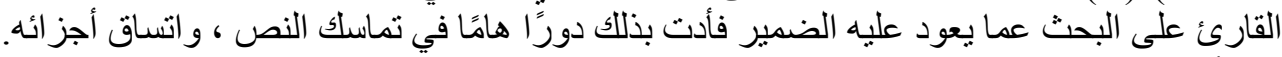

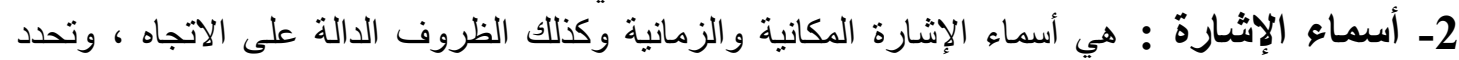

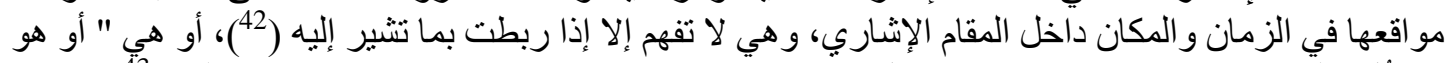

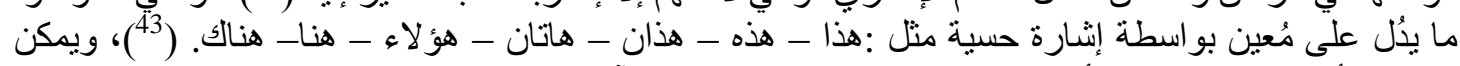

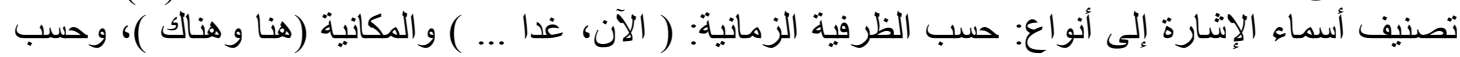

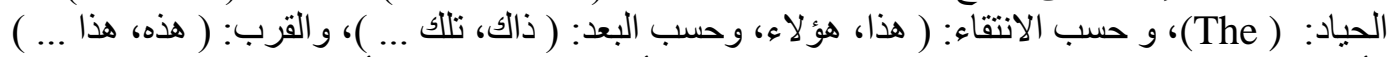

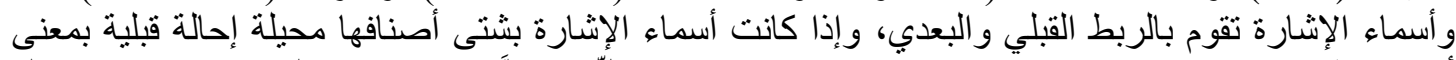

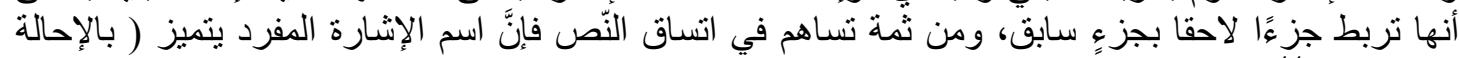

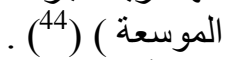
ومن أمثلة ذلك في مفتاح العلوم " كون المسند إليه اسم إثنارة في علم المعاني قوله: ( كما تقول في مقام التعظيم

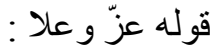

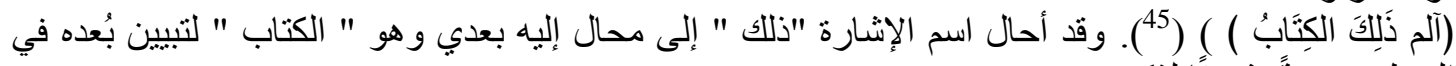

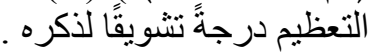

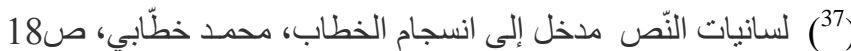
(38) مفتاح العلوم، يوسف بن أبي بكر محمد علي السّكاكي ، ضبطه نعيم زرزور، ص صلئ 336، ط 2، 1987م، دار الكتب

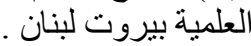

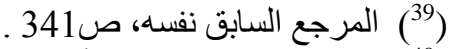

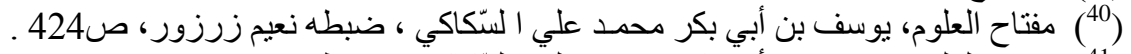

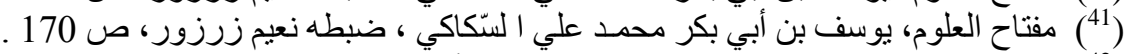

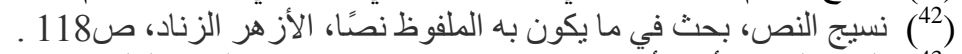

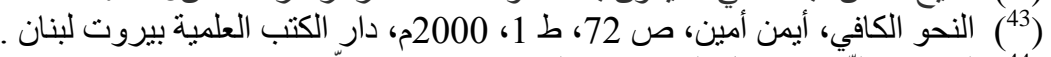

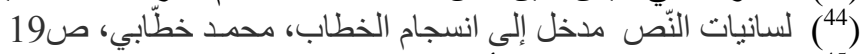
(45) مفتاح العلوم، يوسف بن أبي بكر محمد علي الستّكاكي ، ضبطه نعيم زرزور، ص184، سورة البقرة الآية (1-2 ) 


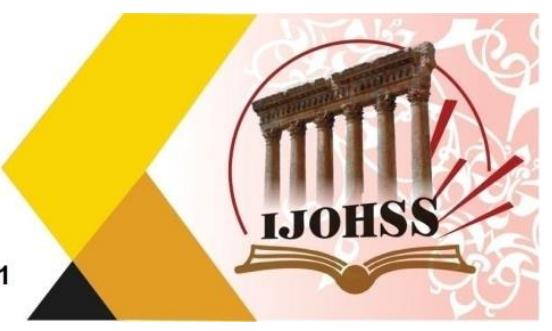

ومن أمنلة ذلك في مفتاح العلوم في علم البيان في أقسام المجاز قوله: ( اعلم أنَّ المجاز عند السلف من علماء هذا

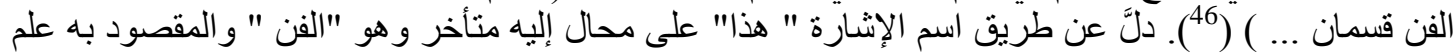

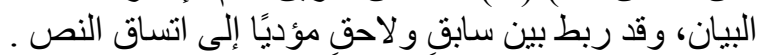

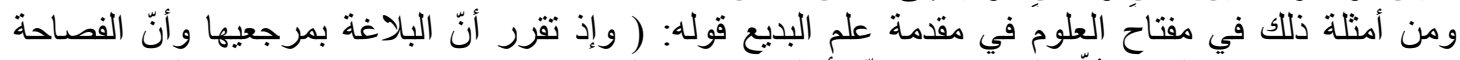

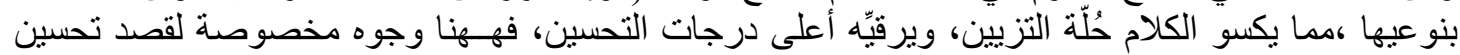

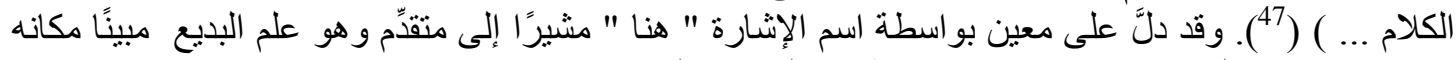

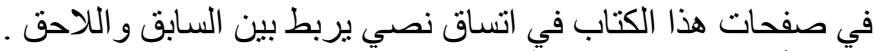

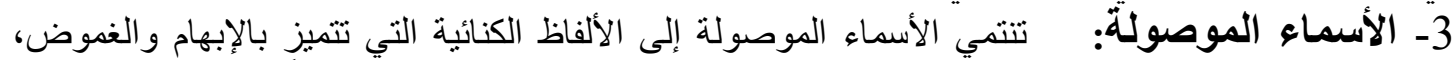

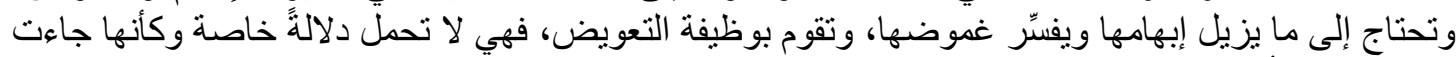

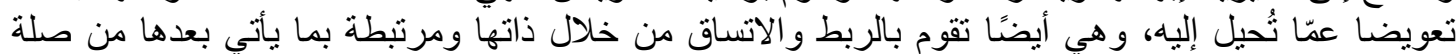

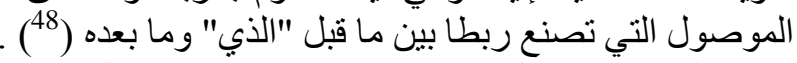

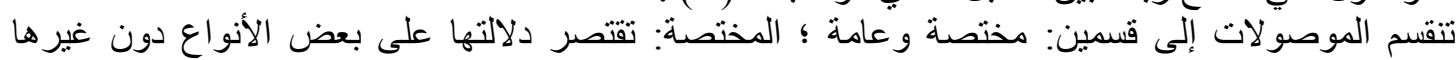

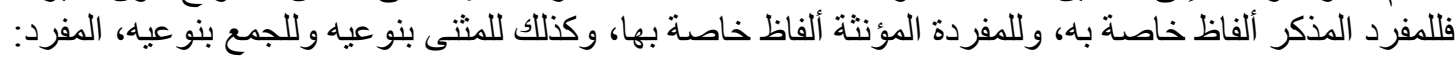

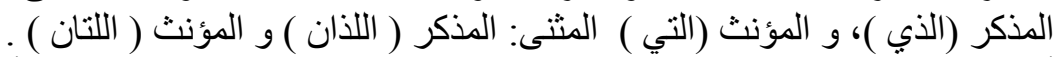

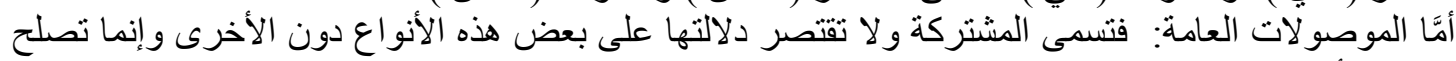

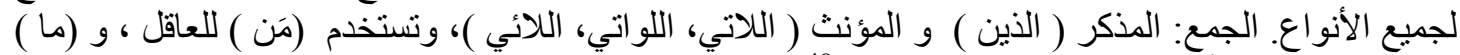

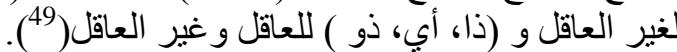

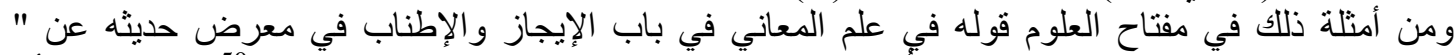

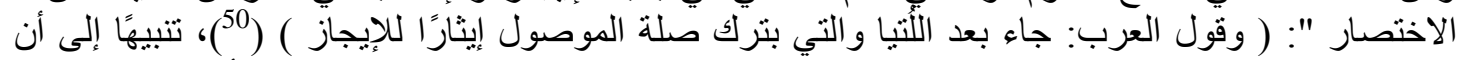

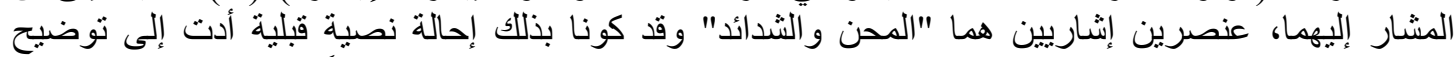

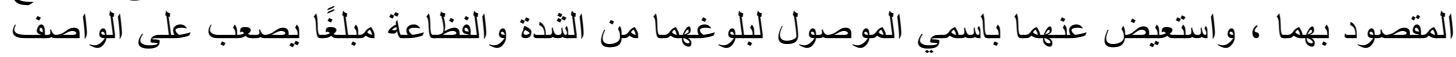

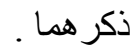

ومن أمثلة ذلك في علم البيان، في حديث السكاكي عن قرينة الاستعارة قوله: ( و واعلم أنَّ قرينة الاستعارة ربما

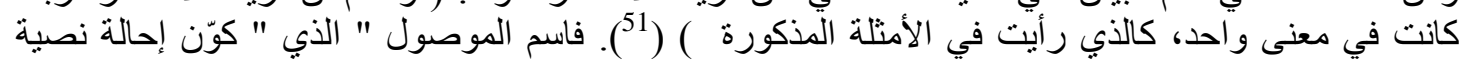

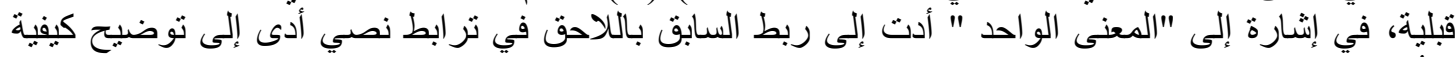

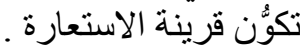

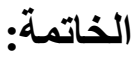

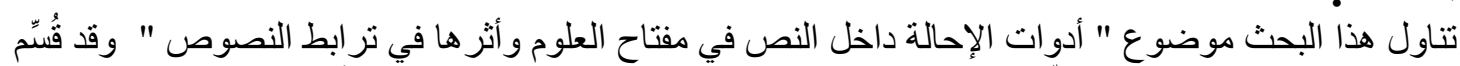

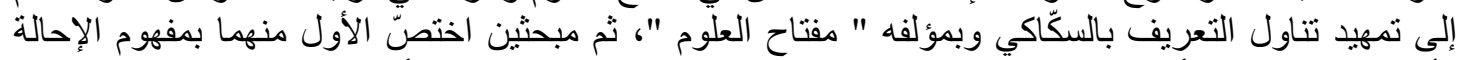

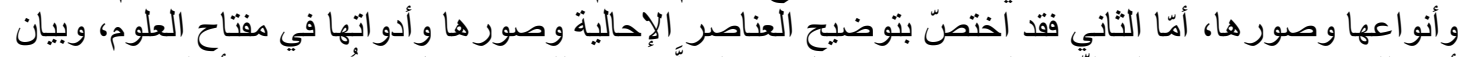

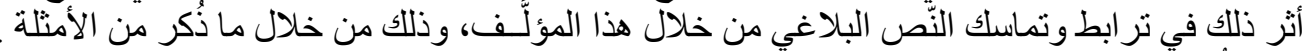

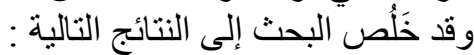

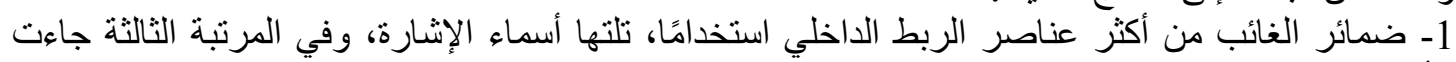

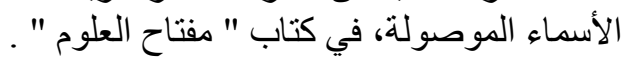

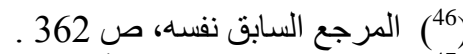

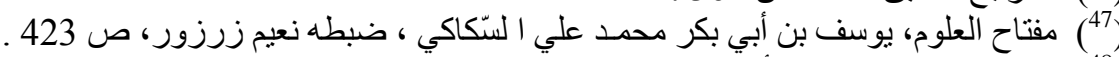

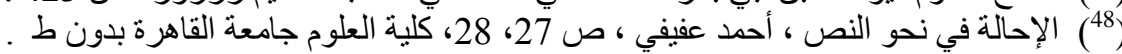

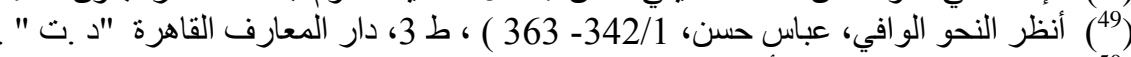

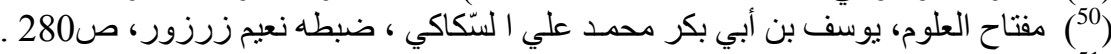

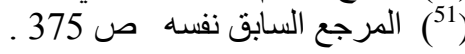




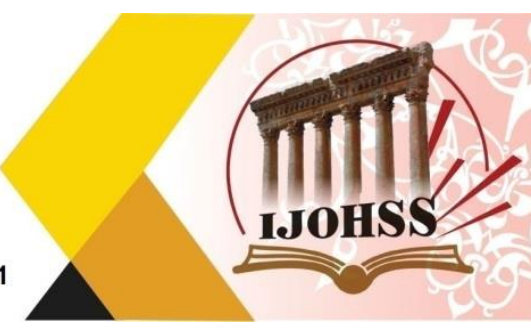

2- أثر الإحالة في " مفتاح العلوم " كان و اضحًا في تبيِّ بينه للمعنى، واختصاره للكلام، وربطه لأجز اء النص

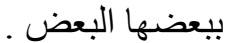
3- معظم الإحالات في مفتاح العلوم " على اختلاف أدو اتها كانت إحالات قبلية .

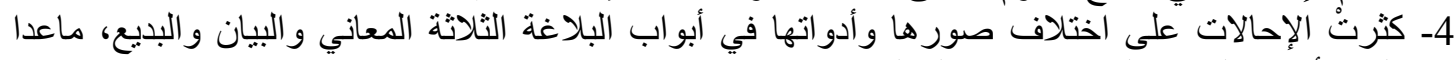

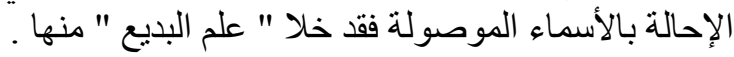

(هذا البحث تمَّ دعمه من خلال البرنامج البحثي العام بعمادة البحث العلمي - بجامعة الملك خالد ـ المملكة

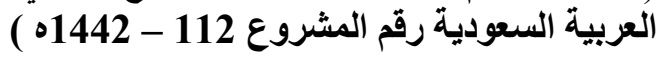

مصادر البحث ومراجعه

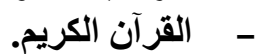

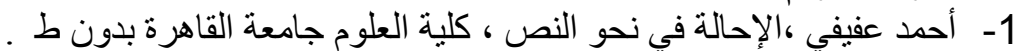
2- خير الدين الزركلي، لأعلام قاموس تراجم لأشهر الرجال الرال والنساء من العرب و المستعربين و المستشرقين ،

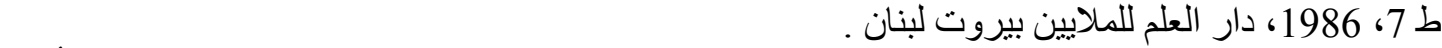
3- عبد الرحمن السيوطي، تحقيق محمـــ أبو الفضل إبراهيم ، بُغية الإيضاح في طبقات اللغويين والنُحاة،

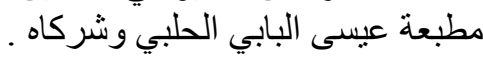

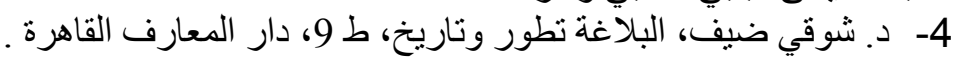

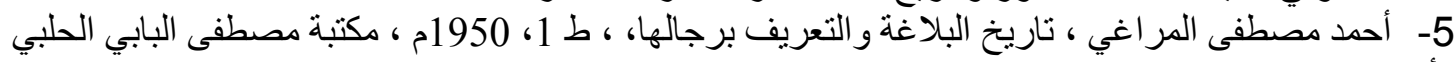

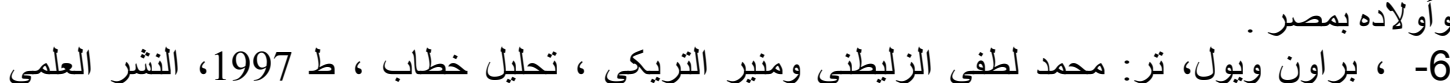

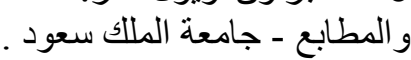

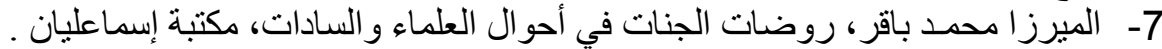

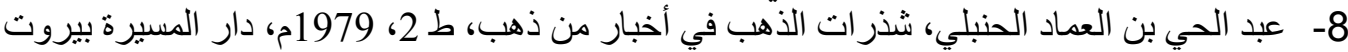

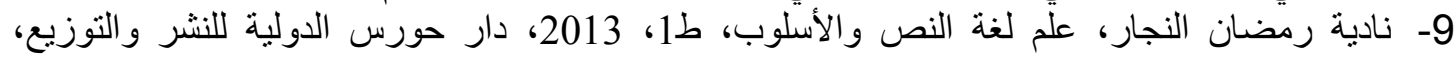

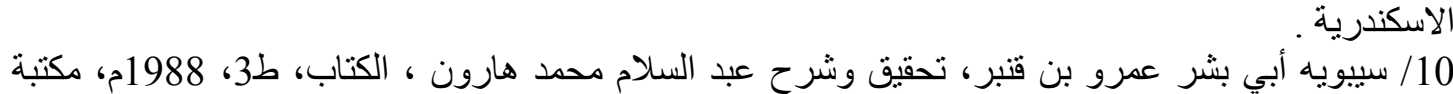

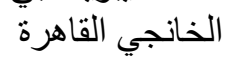
11/ جلاّل الدين السيوطي، لُب الألباب في تحرير الأنساب، مكتبة المثنى بغداد .

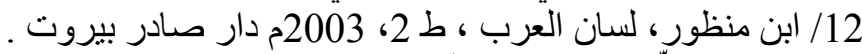
13/ محمد خطنّابي، لسانيات النّص مدخ مدخل إلى انسجام الخطاب، ط 3، 3، 2012، المركز الثقافي العربي، الدار

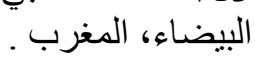
14/ نعمان بوقرة ، المصطلحات الأساسية في لسانيات النص وتحليل الخطاب دراسة معجمية، ط1، 2009،

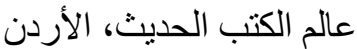
15/ يوسف بن أبي بكر محمد علي الستّكاكي ، ضبطه نعيم زرزور، مفتاح العلوم، ط 2، 1987م، دار الكتب

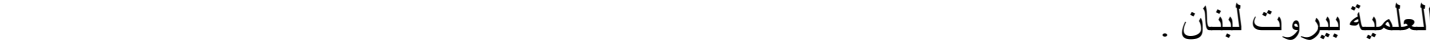
16/ عمر رضا كِّالة، معجم المؤلفين نر اجم مصنفي الكتب العربية، دار إحياء التراث العربي للطباعة و النشر

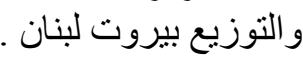

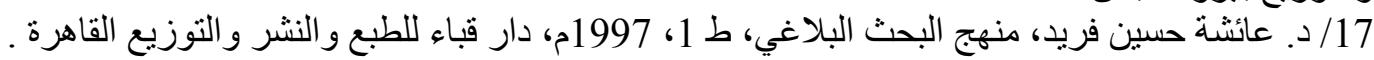

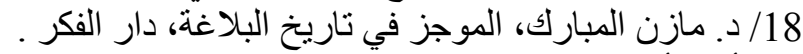

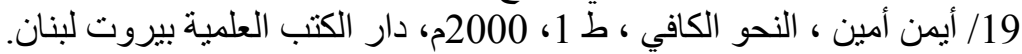

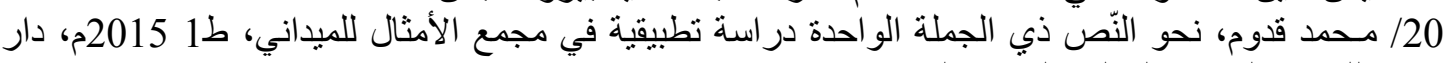
وجوه للنشر و التوزيع المملكة العربية السعودية. 


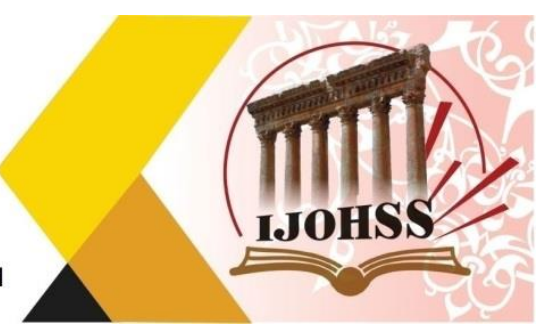

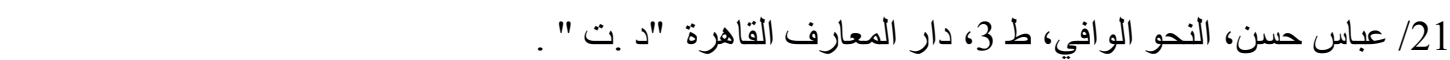

22/ الأزهر الزناد، نسيج النص، بحث في ما يكون به الملفوظ نصنًا، ط 1، 1993م، المركز الثنافي العربي

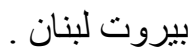

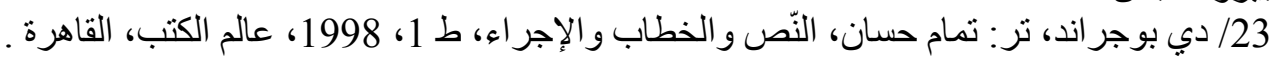

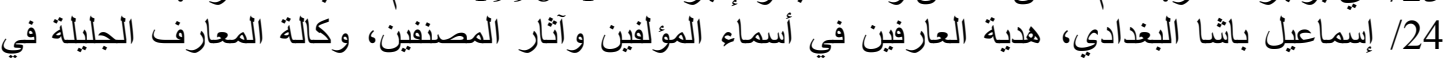

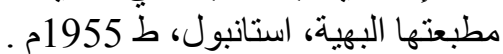

\section{References}

-The Holy Quran.

1- Ahmed Afifi, Referral in Text Grammar, Faculty of Science, Cairo University, without edition.

2- Khair Al-Din Al-Zarkali, Al-Alam, a dictionary of translations of the most famous Arab men and women, Arabists and orientalists, 7th edition, 1986, Dar Al-Ilm for Millions, Beirut, Lebanon.

3- Abdul Rahman Al-Suyuti, investigated by Muhammad Abu Al-Fadl Ibrahim, In order to clarify the layers of linguists and grammarians, Issa Al-Babi Al-Halabi and Co. Printing house.

4 - d. Shawky Deif, Rhetoric evolution and history, 9th edition, Dar Al-Maaref, Cairo.

5- Ahmed Mustafa Al-Maraghi, The history of rhetoric and introducing its men, 1st Edition, 1950 AD, Mustafa Al-Babi Al-Halabi and his sons library in Egypt.

6- Brown and Yule, Translation: Muhammad Lutfi Al-Zulaitni and Munir Al-Treki, Analysis of speech, Edition 1997, Scientific Publishing and Printing house - King Saud University.

7- Mirza Muhammad Baqir, Kindergartens of Paradise in the Status of Scholars and Masters, Ismailian Library.

8. Abdul Hai Bin Hambali Gold nuggets in the news of gold, Gen., 2nd edition, 1979, Dar march Beirut.

9- Nadia Ramadan Al-Najjar, The Science of Text Language and Style, 1st Edition, 2013, Horus International House for Publishing and Distribution, Alexandria.

10- Sibawayh Abi Bishr Amr bin Qanbar, investigation and explanation by Abd alSalam Muhammad Harun, The book, 3rd edition, 1988 AD, Al-Khanji Library, Cairo.

11. Jalal elddin Suyuti, Pulp minds in the liberation of genealogy, Muthanna Baghdad library.

12- Ibn Manzur ، Lisan Al-Arab ، 2nd Edition, 2003 AD, Dar Sader Beirut.

13- Muhammad Khattabi, The Linguistics of the Text: An Introduction to the Harmony of Discourse, 3rd Edition, 2012, The Arab Cultural Center, Casablanca, Morocco.

14- Nouman Bougherra, Basic Terminology in Text Linguistics and Discourse Analysis, A Lexical Study, 1st Edition, 2009, Modern Book World, Jordan.

15 - Youssef bin Abi Bakr Muhammad Ali Al-Sakaki, compiled by Naim Zarzour, Miftah Al-Ulum, 2nd Edition, 1987 AD, Dar Al-Kutub Al-Ilmia, Beirut, Lebanon. 


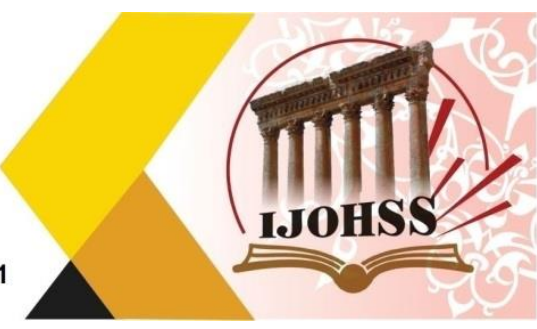

16- Omar Reda Kahala ، Dictionary of Authors, Translations of Compilers of Arabic Books, , Dar Iihya' alturath alearabii for Printing, Publishing and Distribution, Beirut, Lebanon.

17- Aisha Hussein Farid, Rhetorical Research Methodology, 1st Edition, 1997 AD, Dar Qubaa for printing, publishing and distribution, Cairo.

18 - Mazen Al-Mubarak, Summary in the history of rhetoric, Dar Al-Fikr.

19- Ayman Amin, Al-Nahwa Al Kafi, 1st Edition, 2000 AD, Dar al-Kutub alIlmiyya, Beirut, Lebanon.

20- Muhammad Qaddoum, Towards the one-sentence text, an applied study in the Mujmae Al'amthal to Elmaydani, 1st Edition 2015, Dar Wojooh Publishing and Distribution, Kingdom of Saudi Arabia.

21- Abbas Hassan, Alnahw Alwafi, 3rd Edition, Dar Al Maaref, Cairo, undated.

22- Al-Azhar Al-Zinad, Texture of the text, a research into what is in the spoken text, 1st Edition, 1993 AD, the Arab Cultural Center, Beirut, Lebanon.

23- Tammam Hassan, Text, Discourse and Procedure, De Beaugrand, translated by: 1st Edition, 1998, Alam Al-Kutub, Cairo.

24- Ismail Pasha Al-Baghdadi, Hadiat Alearifin in the Names of the Authors and the Effects of the Classifiers, The Glorious Knowledge Agency in its Gorgeous Press, Istanbul, $1955 \mathrm{AD}$. 